\title{
Reduction of Atmospheric Polychlorinated Dibenzo-p-Dioxins and Dibenzofurans (PCDD/Fs) during the 2008 Beijing Olympic Games
}

\author{
Yingming Li, ${ }_{+}^{+}$Thanh Wang, ${ }^{\dagger}$ Pu Wang, ${ }^{\dagger}$ Lei Ding, ${ }^{\dagger}$ Xiaomin Li, Yawei Wang, ${ }^{\dagger}$ Qinghua Zhang, ${ }^{*}{ }^{\dagger}$ An Li, ${ }^{\dagger}$ and \\ Guibin Jiang ${ }^{\dagger}$
}

${ }^{\dagger}$ State Key Laboratory of Environmental Chemistry and Ecotoxicology, Research Center for Eco-Environmental Sciences, Chinese Academy of Sciences, Beijing 100085, People's Republic of China,

${ }^{\ddagger}$ School of Public Health, University of Illinois at Chicago, Chicago, Illinois 60612, United States

Supporting Information

ABSTRACT: A total of 120 air samples were collected at three urban and one rural location in Beijing, China in the summers of 2007-2010, and before, during, and after the Beijing 2008 Olympic Games (BOG), in order to assess the effectiveness of long-term and shortterm emission-control measures in reducing polychlorinated dibenzo- $p$-dioxins and dibenzofurans (PCDD/Fs) in the atmosphere. During the BOG (August, 2008), the PCDD/Fs concentrations decreased to an average value of $1150 \mathrm{fg} \mathrm{m}^{-3}\left(63 \mathrm{fg} \mathrm{I}^{-T E Q \mathrm{~m}^{-3}}\right)$, which was reduced by approximately $70 \%$ from the average in 2007 and by $29 \%$ from that in July 2008 , before the Olympic event began. Although 2009-2010 levels of PCDD/Fs were significantly higher than 2008, the overall temporal trend was decreasing for summer months during the sampling campaign period. The apparent half-lives of atmospheric PCDD/Fs were estimated

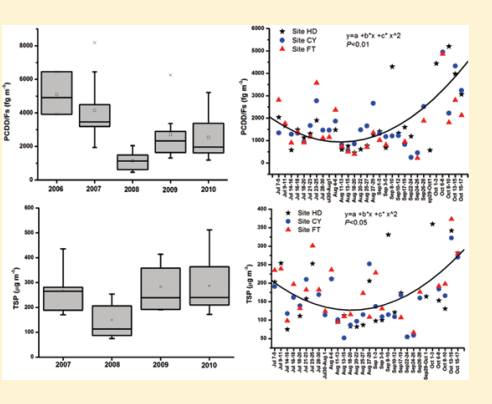
to be $3.2-5.8$ years by statistically regressing the logarithm PCDD/Fs concentrations versus the number of years passed since 2006. The air concentrations of total suspended particulates (TSP) during the BOG ranged between 135 and $183 \mu \mathrm{g} \mathrm{m}^{-3}$, showing a $52 \%$ reduction from 2007 and 26\% decrease from those prior to the Olympic event. No significant relationships were found between meteorological parameters (temperature, humidity, and wind speed) and PCDD/Fs or TSP during the BOG, whereas the PCDD/ Fs concentrations were significantly dependent on the air quality $(p<0.05$, positive against TSP and negative against visibility). This work is one of few temporal trend studies of atmospheric PCDD/Fs in mainland China, and provides unique insight into the effects of large-scale control measures in improving air quality and reducing one of the most ubiquitous and toxic organic pollutants in the environment.

\section{INTRODUCTION}

Polychlorinated dibenzo-p-dioxins (PCDDs) and dibenzofurans (PCDFs) are persistent and toxic organic pollutants that can be formed inadvertently and released during various industrial operations such as combustion processes, metalworking operations, and chemical manufacturing. ${ }^{1}$ Of the 75 PCDDs and 135 PCDFs, the seventeen 2,3,7,8-substituted congeners are most toxic and have been assigned toxic equivalent factors (TEFs). ${ }^{2,3}$ Atmospheric transport is considered as a major pathway for the transfer of PCDD/Fs to terrestrial and aquatic ecosystems. ${ }^{4}$ The atmospheric distribution and fate of PCDD/Fs have been investigated in urban ${ }^{5-8}$ and rural sites ${ }^{9,10}$ around the world, and even in the polar regions. ${ }^{11,12}$ Although the air quality in Chinese major cities has been largely improved in recent years, ${ }^{13}$ detailed monitoring of atmospheric PCDD/Fs is still scarce. Several studies have been conducted on emissions from point sources such as e-waste recycling activities, ${ }^{14}$ industrial processes, ${ }^{15}$ and waste incineration plants. ${ }^{16}$ However, measurements of PCDD/Fs in the ambient air have mostly been limited to several Chinese megacities in the period of 2004-2006, such as Beijing, ${ }^{17}$ Guangzhou, ${ }^{18}$ and Shanghai. ${ }^{19}$ Prior to this study, no long-term monitoring data of atmospheric PCDD/Fs in mainland China were available.
Rapid economic development in China has led to ongoing population growth and high traffic density in the nation's capital, Beijing (17 million people and 4 million vehicles in 2009). The increased anthropogenic activities have contributed to the deteriorating air quality in Beijing. Before and during the 2008 Beijing Olympic Games (August 2008, BOG), the local municipal government made substantial efforts to improve the city's air quality. In particular, the government expedited the implementation of comprehensive emission-control measures, including relocating or closing heavily polluting industries, modifying coal-fired facilities to use natural gas, applying new vehicle emission standards, and implementing temporary restrictions on vehicle use during the BOG. ${ }^{20-22}$ In this work, we collected air samples at several sites in Beijing from summer 2007 to summer 2010 and before, during, and after the 2008 Beijing Olympic Games. Our objectives were to investigate current contamination levels and temporal trends of PCDD/Fs in the

Received: November 22, 2010

Accepted: March 2, 2011

Revised: $\quad$ March 1, 2011

Published: March 21, 2011 
atmosphere of Beijing, and further to assess the effectiveness of emission-control measures in reducing atmospheric PCDD/Fs during the BOG. Influencing factors associated with the PCDD/ Fs variations were also discussed.

\section{EXPERIMENTAL SECTION}

Sample Collection. Air samples were collected using highvolume air samplers (GPS-1, Thermo Environmental Instruments, Inc., Franklin, MA) at an interval of 24 or 48 h. A total of 120 air samples were collected from July to October of 2007-2010. The prevailing wind direction was southeast throughout most of the sampling campaigns. Data on meteorological conditions (temperature, humidity, and wind speed) were collected from online sources (http://www.wunderground. com), and the averages during the 24 or $48 \mathrm{~h}$ sampling period were used (Tables S1-S5 of the Supporting Information,SI). The air volumes sampled are listed in Tables S1-S5 of the SI. Three urban sites (HD, CY, and FT) are located in northern (Haidian district, HD), eastern (Chaoyang district, $\mathrm{CY}$ ), and southwestern (Fengtai district, FT) Beijing. The rural site CP is situated in the Changping district, about $40 \mathrm{~km}$ from the urban center of Beijing (see Figure S1 of the SI). The sampling was performed in accordance with the revised EPA Method TO 9A. ${ }^{23}$ Glass fiber filters (GFF) and polyurethane foam (PUF) plugs were used for collecting particle-bound and gaseous PCDD/Fs, respectively. The GFFs were weighed before and after sampling to obtain the total suspended particulates (TSP) concentrations. The detailed sampling procedure is described in the SI.

Sample Analysis. Analysis of the seventeen 2,3,7,8-subsituted PCDD/Fs followed the US EPA Method 1613B. Each glass fiber filter and PUF plug was combined and then spiked with $1 \mathrm{ng}$ each of ${ }^{13} \mathrm{C}_{12}$-labeled surrogate standards of $15 \mathrm{PCDD} / \mathrm{Fs}$ before an accelerated solvent extraction (ASE) with organic solvents (hexane: dichloromethane: $1: 1$ ). The extracts were concentrated by a rotary evaporator and subjected to cleanup procedure with multilayer silica gel columns, followed by basic alumina and Florisil columns. The final extract was concentrated to $20 \mu \mathrm{L}$ and then spiked with $10 \mu \mathrm{L}$ nonane and $1 \mathrm{ng}{ }^{13} \mathrm{C}_{12}$-labeled injection standards $\left({ }^{13} \mathrm{C}_{12}-1,2,3,4-\mathrm{TCDD}\right.$ and $\left.{ }^{13} \mathrm{C}_{12}-1,2,3,7,8,9-\mathrm{HxCDD}\right)$ for recovery quantification. Detailed analytical procedure can be found in our previous studies. ${ }^{24}$

An Agilent 6890 gas chromatograph (GC) coupled with a Micromass Autospec Ultima high-resolution mass spectrometer (HRMS) was used for instrumental analysis. The HRMS was operated in the electron impact ionization mode at resolution of $R \geq 10000$. A volume of $1 \mu \mathrm{L}$ extract was injected into the GC equipped with a $60 \mathrm{~m}$ DB-5MS column by using a CTC PAL autosampler. The electron emission energy was set at $35 \mathrm{eV}$, and the source temperature was $270{ }^{\circ} \mathrm{C}$. The GC oven temperature was set as follows: $160^{\circ} \mathrm{C}, 2 \mathrm{~min}, 7.5^{\circ} \mathrm{C} \mathrm{min}{ }^{-1}$ to $220^{\circ} \mathrm{C}, 16 \mathrm{~min}$, $5{ }^{\circ} \mathrm{C} \mathrm{min}{ }^{-1}$ to $235^{\circ} \mathrm{C}, 7 \mathrm{~min}, 5^{\circ} \mathrm{C} \mathrm{min}{ }^{-1}$ to $330{ }^{\circ} \mathrm{C}, 1 \mathrm{~min}$.

Quality Assurance and Quality Control. Five pairs of duplicate air samples were collected and the relative standard deviations (RSD) of PCDD/Fs concentrations were $<25 \%$. Field and laboratory blank samples were routinely analyzed in this work for the purpose of quality control. Blank values were very low or below the detection limits (LOD) in most cases, which were defined as three times the signal/noise ratio. The LOD for the air samples was $3-24 \mathrm{fg} \mathrm{m}^{-3}$ for TCDD/Fs, $4-39 \mathrm{fg} \mathrm{m}^{-3}$ for $\mathrm{PeCDD} / \mathrm{Fs}, 3-19 \mathrm{fg} \mathrm{m}^{-3}$ for $\mathrm{HxCDD} / \mathrm{Fs}, 2-16 \mathrm{fg} \mathrm{m}^{-3}$ for $\mathrm{HpCDD} / \mathrm{Fs}$, and $2-14 \mathrm{fg} \mathrm{m}^{-3}$ for OCDD/Fs, respectively.
Surrogate recoveries ranged $40-114 \%$ for TCDD/Fs, $48-131 \%$ for $\mathrm{PeCDD} / \mathrm{Fs}, \quad 36-86 \%$ for $\mathrm{HxCDD} / \mathrm{Fs}, 38-90 \%$ for $\mathrm{HpCDD} / \mathrm{Fs}$, and $40-86 \%$ for OCDD. In the cases when concentrations were below the detection limits, their concentrations were taken as zero. We have participated in the international intercalibration study of $\mathrm{PCDD} / \mathrm{Fs}^{25}$ and the results further validated the analytical method used in this work.

\section{RESULTS AND DISCUSSION}

Air Concentrations of PCDD/Fs. The TSP concentrations are given in Tables $\mathrm{S} 1-\mathrm{S} 5$ of the SI. The results for PCDD/Fs at different sampling sites during the summers of 2007-2010 are summarized in Table S6 of the SI. The $\Sigma$ PCDD/F concentrations ranged between 220 and $27000 \mathrm{fg} \mathrm{m}^{-3}$. No significant difference was observed among the three urban sites (ANOVA, Tukey's post hoc test, $p>0.7$ ), although the FT site is located along the Fourth Ring Road and may receive more emissions from traffic vehicles. However, the PCDD/Fs at the rural site were significantly lower than the three urban sites (Tukey's post hoc test, $p<0.05$ ), which could be attributed to lower population density, sparse traffic, and fewer industrial activities in the rural area. This urban - rural concentration gradient in the atmosphere has previously been reported for other POPs ${ }^{26,27}$ and the results from this work provide further confirmation of urban areas as emission sources of PCDD/Fs to the ambient air.

The TEQ values, calculated using International Toxicity Equivalency Factors, ${ }^{2}$ were in the range of 5-470 $\mathrm{fg} \mathrm{I}^{-T E Q ~ \mathrm{~m}^{-3}}$. As expected, the rural site presented significantly lower TEQs $(p<0.05)$ in comparison with those urban areas. These results are considerably lower than the ambient air standard of $600 \mathrm{fg}$ TEQ $\mathrm{m}^{-3}$ for dioxins proposed by the government of Japan and generally within the global urban PCDD/Fs range of 100-400 fg TEQ $\mathrm{m}^{-3}$, reported by Lohmann and Jones. ${ }^{28}$ Yu et al. found that the PCDD/Fs concentrations in Guangzhou air were in the range of 57-1279 $\mathrm{fg}$ I-TEQ $\mathrm{m}^{-3}$ during a short sampling period in August 2004. ${ }^{18} \mathrm{Li}$ et al. reported PCDD/Fs levels in Shanghai air at the range of $2.2-20760 \mathrm{fg}$ I-TEQ $\mathrm{m}^{-3}$ during one week sampling in March 2006. ${ }^{19}$ By comparison, the atmospheric $\mathrm{PCDD} / \mathrm{Fs}$ concentrations in this work were lower than those in Guangzhou and Shanghai. We also compared the results of this work with those reported for other Asian cities, European countries, and the United States. For example, the PCDD/Fs concentrations in Asia were reported in the range of 49-53 fg I-TEQ $\mathrm{m}^{-3}$ for Hong Kong in 2009, ${ }^{29}$ and $4.2-580 \mathrm{fg}^{\mathrm{TEQ}} \mathrm{m}^{-3}$ for Japan in $2007 .^{30}$ In European countries, PCDD/Fs levels were a few $100 \mathrm{fg}^{\mathrm{T}}$ TEQ $\mathrm{m}^{-3}$ in the early $1990 \mathrm{~s}$ and $<50 \mathrm{fg}^{\mathrm{TEQ}} \mathrm{m}^{-3}$ in the mid-2000s for urban air in the U.K. ${ }^{5}$ and 10-357 fg I-TEQ ${ }^{-3}$ for Spain during 1994-2004. ${ }^{7}$ In the United States, PCDD/Fs were reported at $6.4-15.4 \mathrm{fg} \mathrm{TEQ}^{-3}$ for rural areas in the United States between 1999 and 2002,31 40-55 fg I-TEQ m ${ }^{-3}$ for Houston in 2002-2003, ${ }^{32}$ and 7-35 $\mathrm{fg}$ WHO-TEQ $\mathrm{m}^{-3}$ for the Great Lakes area in 2004-2007..$^{8}$ Considering that the $\mathrm{PCDD} / \mathrm{Fs}$ concentrations during the winter months were on average about $2-3$ times higher than during the summer in Beijing air, ${ }^{17}$ the expected annual PCDD/Fs levels in the Beijing air would be comparable to or slightly higher than those in other urban areas.

Temporal Trend (2006-2010). To better investigate temporal trends of PCDD/Fs and assess whether the current emission-control measures are effective in reducing atmospheric $\mathrm{PCDD} / \mathrm{Fs}$, we compared the $\Sigma \mathrm{PCDD} / \mathrm{F}$ concentrations in the 

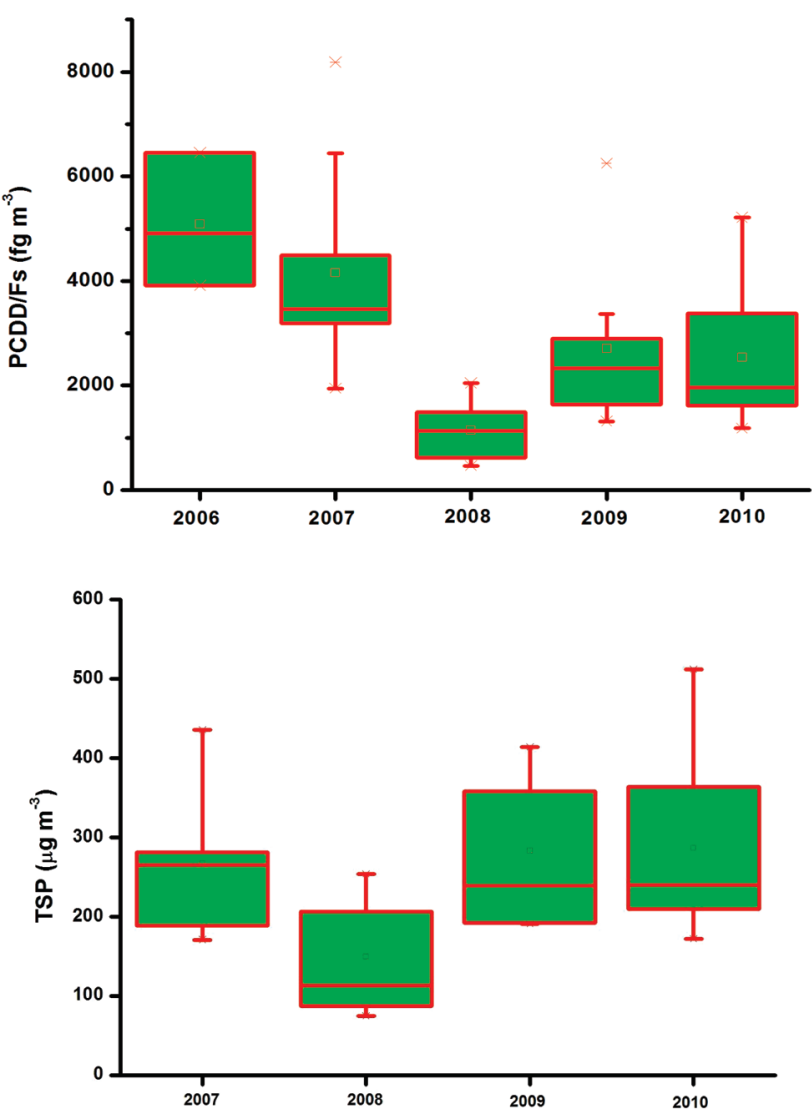

Figure 1. Temporal trends of PCDD/Fs and TSP concentrations at site $\operatorname{HD}\left(n=3\right.$ for $2006,{ }^{17} n=18$ for $2007, n=14$ for $2008, n=10$ for $2009, n=$ 11 for 2010). The horizontal line, box, and whisker represent the median, 25th, and 75th percentiles, and the 5th and 95th percentiles, respectively.

atmosphere of Beijing between 2006 and 2010 (Figure 1). The monitoring time was from July to August in each year to allow consistent comparison.

With the exclusion of the data for July-August 2008 (the Olympic event), the overall temporal trend of $\Sigma \mathrm{PCDD} / \mathrm{Fs}$ is clearly decreasing for summer months during the five year study period. High PCDD/Fs concentrations were found in 2006, with an average of $4719 \mathrm{fg} \mathrm{m}^{-3}\left(309 \mathrm{fg} \mathrm{I}^{-T E Q ~ ~^{-3}}\right)$. The average level has been decreasing since then, to $3828 \mathrm{fg} \mathrm{m}^{-3}$ (230 fg $\mathrm{I}^{-T E Q \mathrm{~m}^{-3}}$ ) in 2007, $2525 \mathrm{fg} \mathrm{m}^{-3}\left(169 \mathrm{fg} \mathrm{I}^{-T E Q ~ \mathrm{~m}^{-3}}\right.$ ) in 2008 with the exclusion of data between July-August, $2705 \mathrm{fg} \mathrm{m}^{-3}$ $\left(189 \mathrm{fg} \mathrm{I}^{-T E Q ~ \mathrm{~m}^{-3}}\right)$ in 2009, and $2421 \mathrm{fg} \mathrm{m}^{-3}\left(137 \mathrm{fg} \mathrm{I}^{-T E Q ~ m}{ }^{-3}\right)$ in 2010. Such trend was best described by a log-linear regression, which corresponds to a first order attenuation pattern. The rate constant of the concentration decrease, which is the slope of natural logarithm PCDD/Fs concentrations versus the number of years after 2006, was $0.22-0.12$ /year, corresponding to an apparent "half-life" of $3.2-5.8$ years, in the $95 \%$ confidence interval $\left(R^{2}=0.99, p=0.004\right.$, excluding 2008 data). A few other studies have also reported declining temporal trends of PCDD/Fs in the atmosphere. For example, Abad et al. observed a $70 \% \mathrm{PCDD} / \mathrm{Fs}$ decrease in Catalonia air from 1997 to 1998 and 2003-2004 in a ten years monitoring study. ${ }^{7}$ Katsoyiannis et al. conducted a long-term monitoring of PCDD/Fs in U.K. air in 1991-2008, and calculated the apparent half-lives of PCDD/Fs in London and Manchester to
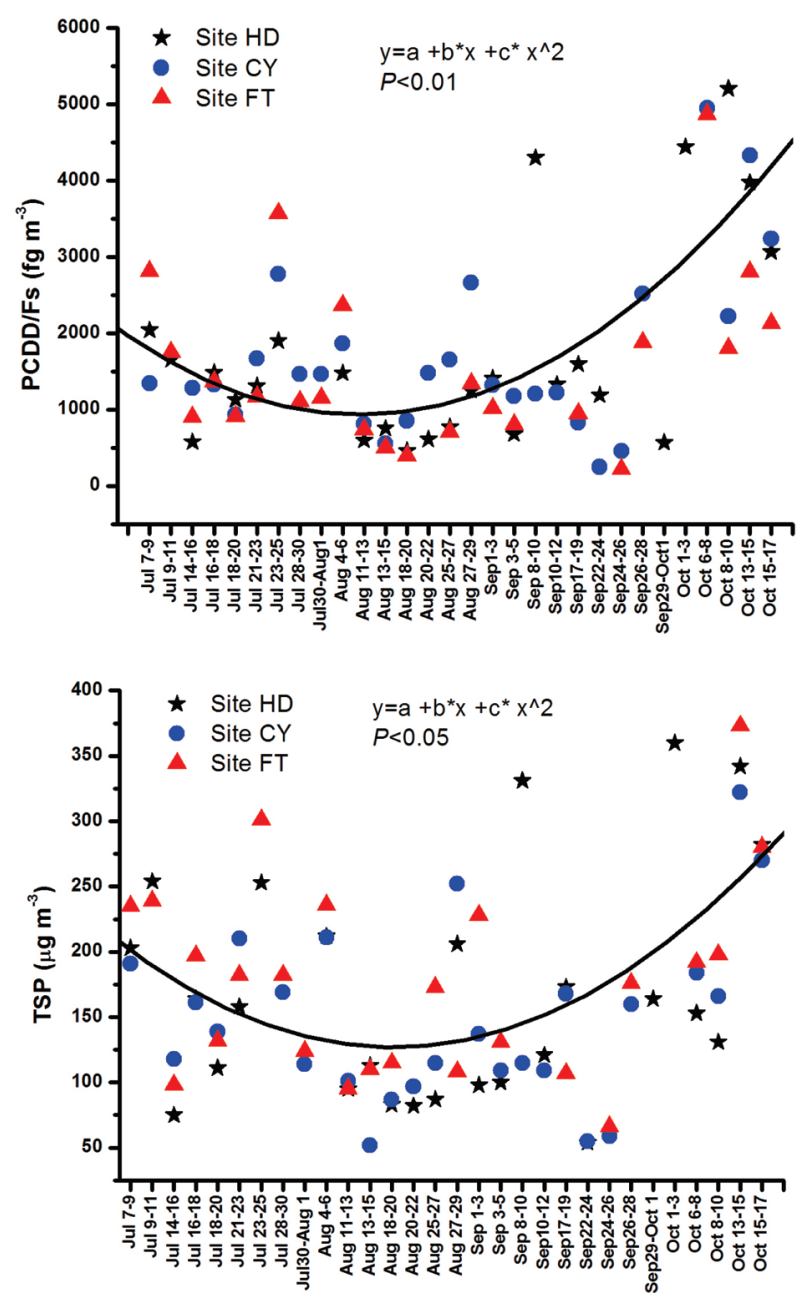

Figure 2. Variations of PCDD/Fs before, during, and after the Beijing Olympic Games in 2008.

be $3.2-5.9$ and $4.1-5.9$ years, respectively. ${ }^{5}$ However, additional monitoring data are needed to confirm that such a declining trend is a global occurrence.

The declining temporal trend of PCDD/Fs in Beijing appears to be associated with the improved air quality, evidenced by a significant correlation between $\Sigma$ PCDD/Fs and TSP concentrations $(p<0.01)$. In the National Eleventh Five-Year Plan (2006-2010), the Chinese government has made increasing efforts in environmental protection, phased out a range of obsolete industrial processes with high consumption of resources and heavy pollution, mandated the installation of catalyst converters on traffic vehicles, and implemented other long-term emission control measures. As a result, the air quality of Beijing has been improving, with a ratio of $14 \%$ for the days meeting the National grade I Air Quality Standard in 2010 compared to $7 \%$ in $2006 .^{13}$

Impact of the Beijing Olympic Games. Between August 8 and August 24 in 2008 during the BOG, Beijing Municipal Government implemented strict vehicle restriction measures. Seventy percent of government cars as well as $50 \%$ of the private cars were banned from the road, reducing $\sim 2$ million on-road automobiles each day during the BOG. ${ }^{21,22}$ Since PCDD/Fs can be emitted from vehicle exhaust, ${ }^{33}$ the decreased vehicle use was expected to result in the reduction of PCDD/Fs emissions to the 
atmosphere. In addition, a number of coal burning factories were temporarily shut down during the BOG.

The $\Sigma \mathrm{PCDD} / \mathrm{F}$ levels in the air responded promptly to these emission control measures, decreasing to an average value of $1146 \mathrm{fg} \mathrm{m}^{-3}\left(63 \mathrm{fg} \mathrm{I}\right.$-TEQ $\left.\mathrm{m}^{-3}\right)$, showing $\sim 70 \%$ reduction from the 2007 level $\left(230 \mathrm{fg}^{\mathrm{I}-T E Q \mathrm{~m}^{-3}}\right.$ ). Figure 2 shows the variation of atmospheric PCDD/Fs at the three urban sites before, during, and after the Olympic Games, which fitted with parabolic regressions $(p<0.05)$ as a function of time. For all of the three urban sites, $\Sigma \mathrm{PCDD} / \mathrm{Fs}$ during the BOG showed significantly lower concentrations compared to July 2008, before the Olympic event began (Tukey's post hoc test, $p<0.05$ ), with an average reduction of $29 \%$. It appears that the reduction of $\mathrm{PCDD} / \mathrm{Fs}$ concentrations became most apparent ten days after the emission control measures were initiated in July 20, 2008. This observation suggests that the emission control measures had a delaying period to take effect. Table S7 of the SI summarizes the average air concentration of each PCDD/F congeners before, during and after the BOG. For the most commonly detected PCDF congeners, the air concentrations were reduced by $40-58 \%$, $17-33 \%$, 49-67\% in comparison with those before the BOG at the urban sites $\mathrm{HD}, \mathrm{CY}$, and $\mathrm{FT}$, respectively. From these results, we conclude that the PCDD/Fs in the ambient air of Beijing have been significantly reduced during the Olympic Games. A reduction trend of $\mathrm{PAH}$ emissions during the BOG was also observed. ${ }^{34}$

The TSP concentrations during the BOG were in the range of 135-183 $\mu \mathrm{g} \mathrm{m}^{-3}$, marking an average reduction of $26 \%$ compared to July 2008, before the Olympic Games began (Figure 2), and a decrease of 52\% compared to 2007 (Figure 1). There is a significant difference of the TSP concentrations in different years (ANOVA, Tukey's post hoc test, $p<$ 0.01). As a result, it can be perceived that the air quality concerning TSP concentrations has been greatly improved during the 2008 Olympic Games. Similar results were also reported by Wang et al. ${ }^{21}$ and Wang et al. ${ }^{35}$

From September to mid-October 2008 after the Olympic Games, $\mathrm{PCDD} / \mathrm{Fs}$ concentrations increased from those during the BOG (Figure 2). No significant correlations can be found between the available meteorological parameters with the individual PCDD/F concentrations in the period shortly after the BOG (Table S8 of the SI), indicating that meteorology did not account for the elevation of PCDD/Fs. However, open burning of crop residues in the field during autumn season could be an important contributor. In China, opening burning is often used as a rapid disposal method of crop residues, which can produce and release a large amount of PCDD/ Fs to the ambient environment. ${ }^{36,37}$ Annual PCDD/Fs emissions from open burning of crop residues contributed appropriately $10-20 \%$ of the total emissions in mainland China between 1997 and 2004. With regard to Beijing and its neighboring city Tianjin and the surrounding province Hebei, PCDD/Fs emissions from open burning of crop residues in 2004 were 6.3, 9.1, and $118 \mathrm{~g}$ I-TEQ, respectively. ${ }^{36}$ More importantly, with the lifting of on-road vehicle restrictions and the resumption of some coal burning industries, increased emissions from these sources and anthropogenic activities could be dominant factors for the elevated PCDD/F concentrations in urban sites after the Olympic Games.

Homologue and Congener Patterns. The congener profiles at the four sampling sites are shown in Figure 3, which is expressed as the relative contribution of individual PCDD/F congeners to the total concentrations and to the total TEQs (TEQ profiles).
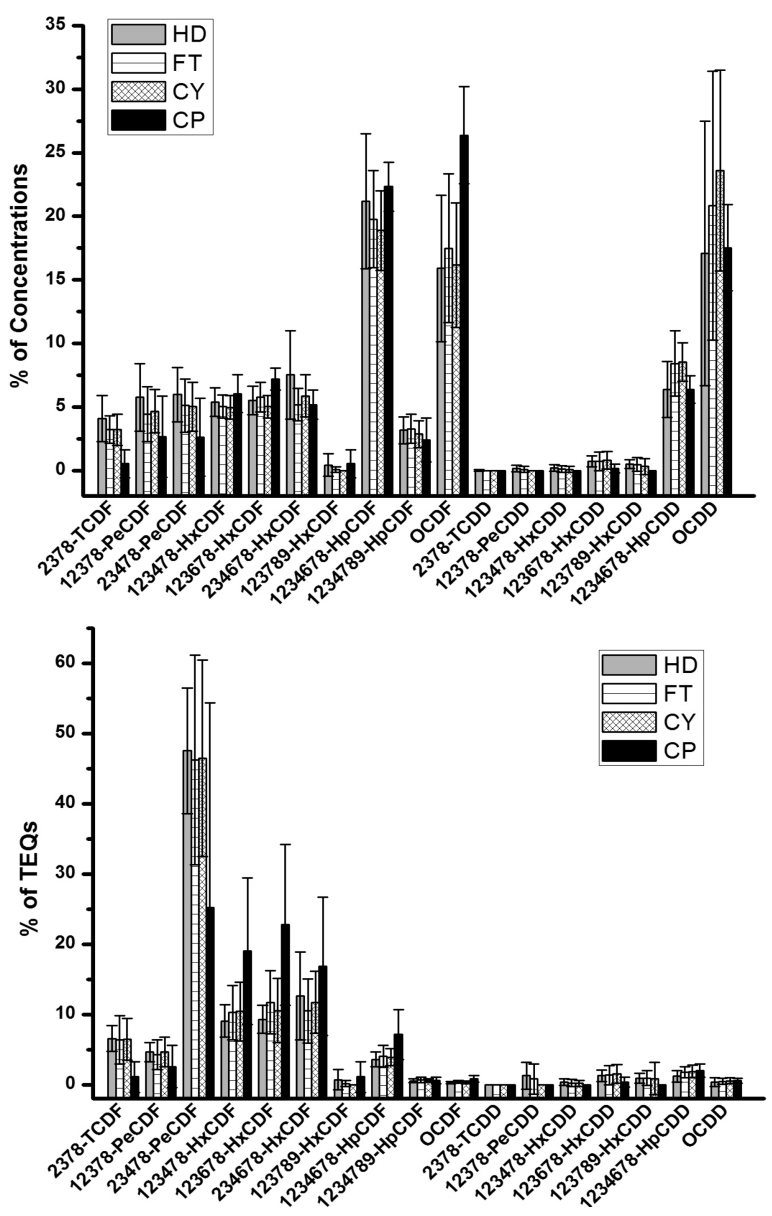

Figure 3. $\mathrm{PCDD} / \mathrm{F}$ profiles $\left(\mathrm{fg} \mathrm{m}^{-3}\right.$ in percentile of concentrations and TEQs) at the four sampling sites.

No significant difference was observed between the contribution of each congener to the total concentration at the rural site and those at the urban areas (Tukey's post hoc test, $p>0.05$ ), indicating a common source or similar transformation process occurring at the rural and urban sites in this work. This result contradicts the findings by Venier et al., ${ }^{8}$ who based their findings on different geographical and industrial activities around the Great Lakes and compared to an unimpacted rural location.

A clear trend of elevated homologue concentrations with increasing levels of chlorination is observed when concentrations of all congeners in each homologue were summarized. Similar observations have been reported in Europe, the United States, Japan, and Australia. ${ }^{28}$ Most PCDF congeners were detected at the four sampling sites, whereas for PCDDs only OCDD and $1,2,3,4,6,7,8-\mathrm{HpCDD}$ were observed in most air samples. The PCDD/PCDF ratio has two extreme values of 0.07 (HD- summer 2009) and 5.4 (HD- Autumn 2008). This could be associated with different emission sources. However, with the exclusion of the two extreme ratios, the PCDD/PCDF ratio showed normal values, which ranged between 0.11 and 1.0. This means that in most cases, combustion-related sources contributed dominantly to the atmospheric PCDD/Fs with PCDD/PCDF ratio lower than 1 . The OCDD, OCDF, and 1,2,3,4,6,7,8-HpCDF congeners dominated the concentration profiles, accounting for $21.9 \pm 11.6 \%$, $17.4 \pm 6.2 \%$, and $19.3 \pm 4.1 \%$ of the total PCDD/Fs, respectively. Other abundant congeners were as follows: $1,2,3,4,6,7,8-\mathrm{HpCDD}$ 
$(7.8 \pm 2.1 \%), 1,2,3,6,7,8-\mathrm{HxCDF}(5.6 \pm 1.3 \%), 2,3,4,6,7,8-\mathrm{HxCDF}$ $(5.4 \pm 1.5 \%), 1,2,3,4,7,8-\mathrm{HxCDF}(5.0 \pm 1.0 \%), 2,3,4,7,8-\mathrm{PeCDF}$ $(5.2 \pm 2.2 \%)$, and $1,2,3,7,8-\operatorname{PeCDF}(4.9 \pm 2.2 \%)$.

With regards to the TEQ profiles, the most abundant congeners (OCDD, OCDF, and 1,2,3,4,6,7,8-HpCDF) did not significantly contribute to the total TEQ values due to their relatively low toxic equivalent factors. However, 2,3,4,7,8PeCDF was the single dominant contributor to the total TEQs $(46.8 \pm 14.1 \%)$. Other minor contributors were $1,2,3,6,7,8$ $\mathrm{HxCDF}, 1,2,3,4,7,8-\mathrm{HxCDF}$, and 2,3,4,6,7,8-HxCDF, accounting for $11.4 \pm 5.1 \%, 10.2 \pm 4.4 \%$, and $10.8 \pm 4.6 \%$ of the total TEQs, respectively. Similar profile results were reported in air samples in Guangzhou, ${ }^{18}$ Shanghai, ${ }^{19}$ the U.K., ${ }^{5}$ Spain, ${ }^{7}$ the Great Lakes region, ${ }^{8}$ and Houston, Texas. ${ }^{32}$

Figure S2 of the SI shows the temporal trends of each PCDD/ $\mathrm{F}$ homologues at site $\mathrm{HD}$. No substantial variations could be observed in this analysis. Even for the period with the lowest PCDD/Fs levels during the 2008 Olympic Games, the homologue composition in concentrations and TEQs did not show obvious variations, indicating similar PCDD/Fs sources and fate in their transport or transformation processes in the atmosphere.

Influence of Meteorology on Individual PCDD/Fs and TSP. Meteorological parameters can influence ambient PCDD/Fs concentrations in certain circumstances. For example, atmospheric PCDD/Fs were reported to show significant inverse relationship with ambient temperature, suggesting domestic heating as an important source during cold periods. ${ }^{38}$ Rainfall has been shown to scavenge PCDD/Fs, but their influence is generally short within 2-3 days. However, Lohmann et al. did not observe significant correlation against rainfalls. ${ }^{39}$ They also found higher PCDD/Fs in the U.K. air during less turbulent air masses with lower wind speed conditions.

In this work, the logarithm concentrations of individual PCDD/ F congeners and TSP were regressed with meteorological parameters (temperature, humidity, and wind speed). The correlation coefficients for the sampling period of 2007, 2009, 2010, and before, during and after the BOG in 2008 are shown in Table S8 of the SI. No significant relationships were found between meteorological parameters and PCDD/Fs or TSP except for a positive correlation against temperature in July 2008 before the BOG began. This result suggests that the ambient temperature, humidity, and wind speed are not responsible for the reductions of $\mathrm{PCDD} / \mathrm{Fs}$ and TSP during the BOG. It should be noted that the influence of wind direction and precipitation on PCDD/Fs emissions should be further investigated due to the lack of data on these two parameters in this study. However, the PCDD/Fs concentrations before, during and after the BOG in 2008 were significantly correlated with the visibility and TSP concentrations $(p<0.05$, positive against TSP and negative against visibility), reflecting the strong dependence of atmospheric PCDD/Fs on the air quality.

\section{ASSOCIATED CONTENT}

S Supporting Information. Figures $S 1$ and S2, Tables S1-S8. This material is available free of charge via the Internet at http://pubs.acs.org.

\section{AUTHOR INFORMATION}

\section{Corresponding Author}

*Tel: +86 10 62849818; Fax: +86 10 62849818; E-mail: qhzhang@rcees.ac.cn.

\section{ACKNOWLEDGMENT}

We thank the National Natural Science Foundation of China (20890111, 20921063, and 20907059), the National Basic Research Program of China (2009CB421605), and the Chinese Academy of Sciences (KJCX2-YW-H04) for financial supports.

\section{REFERENCES}

(1) Alcock, R. E.; Jones, K. C. Dioxins in the environment: A review of trend data. Environ. Sci. Technol. 1996, 30, 3111-3143.

(2) NATO. International toxicity Equivalency (I-TEF) method of risk assessment for complex mixtures of dioxins and related compounds. Pilot study on international information exchange on dioxins and related compounds. Report No. 176, 1988.

(3) Van Berg, M.; Birnbaum, L.; Bosveld, A. T. C. Toxic Equivalency Factors (TEFs) for PCBs, PCDDs, PCDFs for humans and wildlife. Environ. Health. Perspect. 1998, 106, 775-792.

(4) Kouimtzis, T. H.; Samara, C.; Voutsa, D.; Balafoutis, C. H.; Müller, L. PCDD/Fs and PCBs in air borne particulate matter of the greater Thessaloniki area, N. Greece. Chemosphere 2002, 47, 193-205.

(5) Katsoyicannis, A.; Gioia, R.; Sweetman, A. J.; Jones, K. C. Continuous monitoring of $\mathrm{PCDD} / \mathrm{Fs}$ in the UK atmosphere: 1991-2008. Environ. Sci. Technol. 2010, 44, 5735-5740.

(6) Tung, J. W. T.; Yu, J. Z.; Lau, A. K. H.; Louie, P. K. K. Abundance and sources of ambient dioxins in Hong Kong: A review of dioxin measurements from 1997 to 2001. Chemosphere 2005, 59, 1387-1398.

(7) Abad, E.; Martínez, K.; Gustems, L.; Gómez, R.; Guinart, X.; Hernández, I.; Rivera, J. Ten years measuring PCDDs/PCDFs in ambient air of Catalonia (Spain). Chemosphere 2007, 67, 1709-1714.

(8) Venier, M.; Ferrario, J.; Hites, R. A. Polychlorinated dibenzo-pdioxins and dibenzofurans in the atmosphere around the Great Lakes. Environ. Sci. Technol. 2009, 43, 1036-1041.

(9) Lee, R. G. M.; Green, N. J. L.; Lohmann, R.; Jones, K. C. Seasonal, anthropogenic, air mass, and meteorological influences on the atmospheric concentrations of polychlorinated dibenzo-p-dioxins and dibenzofurans (PCDD/Fs): Evidence for the importance of diffuse combustion sources. Environ. Sci. Technol. 1999, 33, 2864-2871.

(10) Menichini, E.; Iacovella, N.; Monfredini, F.; Turrio-Baldassarri, L. Atmospheric pollution by PAHs, PCDD/Fs and PCBs simultaneously colleted at a regional background site in central Italy and at an urban site in Rome. Chemosphere 2007, 69, 422-434.

(11) Hung, H.; Blanchard, P.; Poole, G.; Thibert, B.; Chiu, C. H. Measurement of particle-bound polychlorinated dibenzo-p-dioxins and dibenzofurans (PCDD/Fs) in Arctic air at Alert, Nunavut, Canada. Atmos. Environ. 2002, 36, 1041-1050.

(12) Lugar, R. M.; Harless, R. L.; Dupuy, A. E.; Mcdaniel, D. D. Results of monitoring for polychlorinated dibenzo-p-dioxins and dibenzofurans in ambient air at McMurdo station, Antarctica. Environ. Sci. Technol. 1996, 30, 555-561.

(13) Report On the State of the Environment In China. Ministry of Environmental Protection of the People's Republic of China. http:// english.mep.gov.cn/standards reports/. 2010.

(14) Ma, J.; Addink, R.; Yun, S. H.; Cheng, J. P.; Wang, W. H.; Kannan, K. Polybrominated dibenzo-p-dioxins/dibenzofurans and polybrominated diphenyl ethers in soil, vegetation, workshop-floor dust, and electronic shredder residue from an electronic waste recycling facility and in soils from a chemical industrial complex in Eastern China. Environ. Sci. Technol. 2009, 43, 7350-7356.

(15) Du, B.; Zheng, M. H.; Tian, H. H.; Liu, A. M.; Huang, Y. R.; Li, L. L.; Ba, T.; Li, N.; Ren, Y.; Li, Y. W.; Dong, S. P.; Su, G. J. Occurrence and characteristics of polybrominated dibenzo-p-dioxins and dibenzofurans in stack gas emissions from industrial thermal processes. Chemosphere 2010, 80, 1227-1233.

(16) Chen, T.; Yan, J. H.; Lu, S. Y.; Li, X. D.; Gu, Y. L.; Dai, H. F.; Ni, M. J.; Cen, K. F. Characteristic of polychlorinated dibenzo-p-dioxins and dibenzofurans in fly ash from incinerators in China. J. Hazard. Mater. 2008, 150, 510-514. 
(17) Li, Y. M.; Jiang, G. B.; Wang, Y. W.; Cai, Z. W.; Zhang, Q. H. Concentrations, profiles and gas-particle partitioning of polychlorinated dibenzo-p-dioxins and dibenzo-furans in the ambient air of Beijing, China. Atmos. Environ. 2008, 42, 2037-2047.

(18) Yu, L. P.; Mai, B. X.; Meng, X. Z.; Bi, X. H.; Sheng, G. Y.; Fu, J. M.; Peng, P. A. Particle-bound polychlorinated dibenzo-p-dioxins and dibenzo-furans in the atmosphere of Guangzhou, China. Atmos. Environ. 2006, 40, 96-108.

(19) Li, H. R.; Feng, J. L.; Sheng, G. Y.; Lu, S. L.; Fu, J. M.; Peng, P. A.; Man, R. The PCDD/F and PBDD/F pollution in the ambient atmosphere of Shanghai, China. Chemosphere 2008, 70, 576-583.

(20) Yu, H.; Wang, P. C.; Zong, X. M.; Li, X.; Lu, D. R. Change of $\mathrm{NO}_{2}$ column density over Beijing from satellite measurement during the Beijing 2008 Olympic Games. Chin. Sci. Bull. 2010, 55, 308-313.

(21) Wang, X.; Westerdahl, D.; Chen, L. C.; Wu, Y.; Hao, J. M.; Pan, $\mathrm{X}$. C. Evaluating the air quality impacts of the 2008 Beijing Olympic Games: On-road emission factors and black carbon profiles. Atmos. Environ. 2009, 43, 4535-4543.

(22) Zhou, Y.; Wu, Y.; Yang, L.; Fu, L.; He, K.; Wang, S.; Hao, J.; Chen, J.; Li, C. The impact of transportation control measures on emission reductions during the 2008 Olympic Games in Beijing, China. Atmos. Environ. 2010, 44, 285-293.

(23) US EPA, Method TO 9A. Determination of polychlorinated, polybrominated and brominated/chlorinated dibenzo-p-dioxins and dibenzofurans in the ambient air, EPA/625/R-96/010b, 1999.

(24) Zhang, Q. H.; Jiang, G. B. Polychlorinated dibenzo-p-dioxins/ furans and polychlorinated biphenyls in sediments and aquatic organisms from the Taihu Lake, China. Chemosphere 2005, 61, 314-322.

(25) Van Bavel, B. Final Report Tenth Round of the International Intercalibration Study; Workgroup International Intercalibration Studies: Sweden, 2005.

(26) Harner, T.; Shoeib, M.; Diamond, M. L.; Stern, G.; Rosenberg, B. Using passive air samplers to assess urban-rural trends for persistent organic pollutants. 1. Polychlorinated biphenyls and organochlorine pesticides. Environ. Sci. Technol. 2004, 38, 4474-4483.

(27) Zhang, Z.; Liu, L. Y.; Li, Y. F.; Wang, D. G.; Jia, H. L.; Harner, T.; Sverko, E.; Wan, X. N.; Xu, D. D.; Ren, N. Q.; Ma, J. M.; Pozo, K. Analysis of polychlorinated biphenyls in concurrently sampled chinese air and surface soil. Environ. Sci. Technol. 2008, 42, 6514-6518.

(28) Lohmann, R. Jones, K. C. Dioxins and furans in air and deposition: a review of levels, behavior and processes. Sci. Total Environ. 2000, 219, 53-81.

(29) Government of Hong Kong. Summary of ambient dioxin level in Hong Kong. http://www.epd-asg.gov.hk/english/report/dioxin09.php. 2009.

(30) Government of Japan. Information brochure dioxins 2009. http://www.env.go.jp/en/chemi/dioxins/brochure2009.pdf. 2009.

(31) Cleverly, D.; Ferrario, J.; Byrne, C.; Riggs, K.; Joseph, D.; Hartford, P. A general indication of the contemporary background levels of PCDDs, PCDFs, and coplanar PCBs in the ambient air over rural and remote locations of the United States. Environ. Sci. Technol. 2007, 41, 1537-1544.

(32) Correa, O.; Rifai, H.; Raun, L.; Suarez, M.; Koenig, L. Concentrations and vapor-particle partitioning of polychlorinated dibenzo$p$-dioxins and dibenzofurans in ambient air of Houston, TX. Atmos. Environ. 2004, 38, 6687-6699.

(33) US EPA. An inventory of sources and environmental releases of dioxin-like compounds in the United States for the years 1987, 1995, and 2000. EPA/600/P-03/002F, 2006.

(34) Jia, Y.; Stone, D.; Wang, W. ; Schrlau, J.; Tao, S.; Simonich, M. Estimated reduction in cancer risk due to $\mathrm{PAH}$ exposures if source control measures during the 2008 Beijing Olympics were sustained. Environ. Health. Perspect. DOI: 10.1289/ehp.1003100.

(35) Wang, W. T.; Primbs, T.; Tao, S.; Zhu, T.; Simonich, S. L. M. Atmospheric particulate matter pollution during the 2008 Beijing Olympics. Environ. Sci. Technol. 2009, 43, 5314-5320.

(36) Yu, G.; Zhang, Q.; Huang, J. Polychlorinated dibenzo-p-dioxins and dibenzofurans emissions from open burning of crop residues in China between 1997 and 2004. Environ. Pollut. 2008, 151, 39-46.
(37) Zheng, G. J.; Leung, A. O. W.; Jiao, L. P.; Wong, M. H. Polychlorinated dibenzo- $p$-dioxins and dibenzofurans pollution in China: Sources, environmental levels and potential human health impacts. Environ. Int. 2008, 34, 1050-1061.

(38) Li, Y. M.; Wang, P.; Ding, L.; Li, X. M.; Wang, T.; Zhang, Q. H.; Yang, H. B.; Jiang, G. B.; Wei, F. S. Atmospheric distribution of polychlorinated dibenzo-p-dioxins, dibenzofurans and dioxin-like polychlorinated biphenyls around a steel plant area, Northeast China. Chemosphere 2010, 79, 253-258.

(39) Lohmann, R.; Green, N. J. L.; Jones, K. C. Detailed studies of the factors controlling atmospheric PCDD/F concentrations. Environ. Sci. Technol. 1999, 33, 4440-4447. 